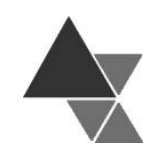

\title{
Hábitos alimentares e produtos ultraprocessados na alimentação escolar: um estudo de caso da Terra Indígena Piaçaguera, São Paulo, Brasil
}

\author{
Vanessa Manfre Garcia de Souza ${ }^{1}$ e Betzabeth Slater Villar ${ }^{2}$
}

Este estudo teve como objetivo analisar o cardápio das escolas indígenas de Piaçaguera - SP, quanto ao respeito aos hábitos alimentares, às diferenças de um cardápio escolar não indígena e à frequência de produtos ultraprocessados. Trata-se de um estudo de caso, realizado na Terra Indígena Piaçaguera, em Peruíbe - SP, onde foram visitadas quatro escolas. A Comissão Pró-Índio de São Paulo disponibilizou materiais com informações sobre Piaçaguera e os hábitos alimentares locais, e seis cardápios mensais da alimentação escolar de 2016. Os cardápios foram analisados por refeição quanto à presença e a combinação de alimentos tradicionais do hábito indígena, e um dos cardápios foi comparado a outro não indígena e analisado quanto à frequência de ultraprocessados. Foi encontrada uma preparação tradicional para cada refeição, uma vez por semana, sendo a única diferença do cardápio não indígena. Os ultraprocessados foram encontrados diariamente no desjejum, alguns dias de forma exclusiva, e de 2 a 3 vezes por semana no almoço. Portanto, os cardápios escolares não condizem com os hábitos alimentares de Piaçaguera e os ultraprocessados estiveram frequentemente presentes. É necessário que o planejamento do cardápio da alimentação escolar considere a variedade de alimentos tradicionais e valorize o patrimônio alimentar indígena.

Palavras-chave: alimentação escolar, população indígena, hábitos alimentares, Programas e Políticas de Nutrição e Alimentação, alimentos industrializados.

\section{Food habits and ultra-processed products in school feeding: a case study of the Piaçaguera Indigenous Land, São Paulo, Brazil}

The objective of this study was to analyze the menu of the indigenous schools of Piaçaguera - SP, regarding the respect to food habits, the differences between the non-indigenous school menu and the frequency of ultraprocessed products. This is a case study, carried out in the Piaçaguera Indigenous Land, in Peruíbe - SP, where four schools were visited. The Pro-Indian Commission of São Paulo provided materials with information on Piaçaguera and local food habits, and six-monthly menus for school meals in 2016 . These menus were analyzed by meal regarding the presence and the combination of traditional foods of the indigenous habit, and one of the menus was compared to the non-indigenous menu and analyzed for the frequency of ultra-processed products. One traditional preparation was found for each meal, once a week, which was the only difference from the nonindigenous menu. The ultra-processed products were found daily at breakfast, some days exclusively, and 2 to 3

${ }_{1}^{1}$ Mestre em Ciências pelo Programa de Pós-Graduação de Nutrição em Saúde Pública da Faculdade de Saúde Pública/USP. Endereço para correspondência: Av. Dr. Arnaldo no 715, São Paulo, SP, Brasil, CEP: 01246-904. Tel: (11) 3061-7701.E-mail: vanessa.manfregs@gmail.com

${ }^{2}$ Professora Associada do Departamento de Nutrição da Faculdade de Saúde Pública/USP. E-mail: bslater@usp.br 
times a week at lunch. Therefore, the school menus do not match the eating habits of Piaçaguera and the ultraprocessed were frequently present. It is necessary that the planning of the school feeding menu consider the variety of traditional foods and value the indigenous food patrimony.

Keywords: school feeding, indigenous population, food habits, Nutrition Programs and Policies, industrialized foods.

\section{INTRODUÇÃO}

Para o povo indígena Guarani, os alimentos têm uma importância que está muito além de nutrir o corpo, pois estão relacionados ao modo de ser e de viver deste povo, à significação religiosa e sua relação com a Divindade, à importância simbólica, como a participação do milho em rituais. Essa valorização também é verificada na diferenciação que este povo faz do que é "alimento do branco" e "alimento do guarani", em que consideram que os cultivares tradicionais dos roçados Guarani como feijão, mandioca, batata-doce, milho, abóbora, amendoim e diversas frutas têm origem divina ${ }^{[1]}$.

As questões de demarcação e de conservação de terras indígenas representam um obstáculo para a agricultura de subsistência e cultivo destes alimentos tradicionais da cultura alimentar. $\mathrm{O}$ relatório da Organização das Nações Unidas para a Alimentação e a Agricultura (FAO) de 2014[2], mostrou que a situação de insegurança alimentar e nutricional da população indígena é urgente, e que essa situação está diretamente vinculada à questão do acesso à terra.

$\mathrm{Na}$ Terra Indígena de Piaçaguera, em PeruíbeSP, local deste estudo, a situação de vulnerabilidade da população foi agravada pela atividade de empresas mineradoras, desde os anos 1960. A extração impactou consideravelmente a vegetação nativa da terra, o que dificulta a realização de roçados pelos indígenas ${ }^{[3]}$.

Dessa forma, garantir a alimentação tem sido um desafio para os índios, que necessitam cada vez mais buscar alimentos na cidade, mas sem poder contar com uma renda constante e suficiente para isso[4].

Consequentemente, houve uma mudança na dieta indígena, caracterizada por um aumento no consumo de produtos ultraprocessados, em detrimento do consumo de alimentos tradicionais $[5,6,7,8]$. Com essa mudança dos hábitos alimentares, conseguir garantir uma alimentação saudável tornou-se uma preocupação recorrente entre os indígenas ${ }^{[9]}$.

Um estudo de 2009, realizado com grupos de etnia Guarani do estado de São Paulo, mostrou que em Piaçaguera, local de estudo deste artigo, houve a adoção de hábitos alimentares próprios de comunidades não indígenas, como o consumo elevado, especialmente pelas crianças, de alimentos ultraprocessados. Este estudo encontrou também mulheres adultas e crianças abaixo de 5 anos de idade com excesso de peso ${ }^{[4]}$.

Diante da situação de vulnerabilidade dessa população, a política de Alimentação Escolar representa uma estratégia de Segurança Alimentar e Nutricional e de realização do Direito Humano à Alimentação Adequada (DHAA) para os estudantes indígenas ${ }^{[10]}$.

O Programa Nacional de Alimentação Escolar (PNAE) estabelece que o cardápio das escolas da rede pública de ensino, inclusive das indígenas, deve ser elaborado de modo a respeitar a cultura alimentar local e pautar-se na alimentação saudável e adequada. Cabe destacar a determinação do Programa de que o cardápio deve atender as especificidades culturais das comunidades indígenas ${ }^{[1]]}$.

Assim, faz-se necessário investigar se a alimentação ofertada pelo Programa de Alimentação Escolar em Piaçaguera está de acordo com os hábitos alimentares locais, com base em alimentos in natura, minimamente processados e preparações culinárias feitas a partir destes alimentos.

Diante do exposto, o presente estudo teve como objetivo analisar o cardápio das escolas indígenas de Piaçaguera - SP, quanto ao respeito aos hábitos alimentares, às diferenças de um cardápio escolar não indígena e à frequência de produtos ultraprocessados. 


\section{METODOLOGIA}

Trata-se de um estudo de caso, fruto de uma consultoria realizada para a Comissão Pró-Índio de São Paulo, em que foi elaborada uma avaliação da alimentação escolar na Terra Indígena Piaçaguera, de acordo com a legislação do PNAE. A Comissão Próíndio é uma organização não-governamental que atua junto com índios e quilombolas para garantir seus direitos territoriais, culturais e políticos ${ }^{[2]}$.

A Terra Indígena Piaçaguera está localizada no município de Peruíbe, litoral sul do estado de São Paulo, onde vivem cerca de 230 índios do povo Tupi-Guarani, divididos em cinco aldeias, as quais abrangem duas escolas estaduais e três salas vinculadas ${ }^{[3]}$. As escolas são de Ensino Infantil e Fundamental, e atendem um total de 61 alunos, segundo o censo escolar consultado no site do Fundo Nacional de Desenvolvimento da Educação (FNDE) ${ }^{[13]}$.

A Prefeitura é responsável pelo Programa de Alimentação Escolar nas escolas municipais e estaduais, incluindo as indígenas, sendo que o fornecimento das refeições foi terceirizado para uma empresa. As merendeiras são indígenas das próprias aldeias onde as escolas estão inseridas.

A Comissão Pró-Índio disponibilizou todos os dados necessários à realização deste estudo: documentos com informações sobre a Terra Indígena; documentos oficiais enviados pelos indígenas às instituições competentes reivindicando mudanças na alimentação escolar, de forma a respeitar sua cultura alimentar, bem como atas de reuniões e registros das rodas de conversa entre representantes indígenas e de órgãos públicos; e seis cardápios mensais das escolas indígenas.

Os dados foram disponibilizados em agosto de 2016 e, após o levantamento de informações sobre a Terra Indígena, foram visitadas quatro escolas, uma em cada aldeia, durante dois dias de setembro, para conhecimento da realidade local.

Para avaliar o respeito aos hábitos alimentares no cardápio da alimentação escolar, foram coletadas informações sobre os alimentos e as preparações tradicionais da cultura alimentar de Piaçaguera, a partir dos materiais disponibilizados pela Comissão PróÍndio, e a partir da visita à Terra Indígena.

Após a coleta dessas informações, foram analisados os cardápios dos meses de março, abril, maio, junho, agosto e setembro de 2016, quanto à presença de alimentos e preparações tradicionais, e se estavam presentes na forma como são consumidos, na combinação com outros alimentos, por exemplo.

Além disso, o cardápio do mês de agosto foi comparado com o cardápio do mesmo mês das escolas públicas não indígenas, de Ensino Fundamental, coletado no Boletim Oficial do Município[14], a fim de verificar se o cardápio indígena era diferenciado, conforme determina o PNAE[11].

Com relação à presença de produtos ultraprocessados no cardápio das escolas, foi considerada a definição que o atual Guia Alimentar para a População Brasileira, do MINISTÉRIO DA SAÚDE $(\mathrm{BR})^{[15]}$, traz para este grupo de alimentos:

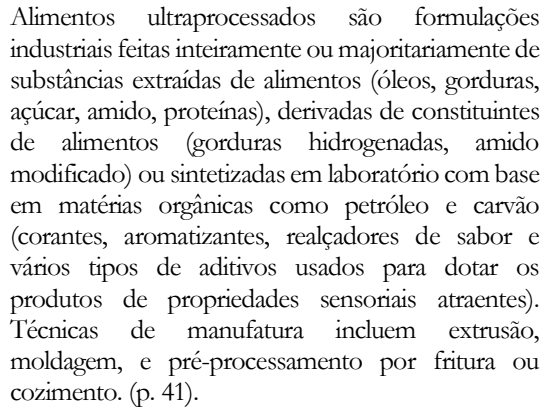

E para definir quais alimentos do cardápio eram ultraprocessados, foram verificadas as informações contidas nos rótulos dos alimentos industrializados, durante a visita às escolas.

Foi analisada a frequência semanal destes produtos, por refeição, referente ao cardápio do mês de agosto de 2016, por ser o mais recente até o momento da avaliação e não conter feriado.

A Comissão Pró-Índio de São Paulo concordou com a divulgação dos resultados deste estudo. 


\section{RESULTADOS}

Durante a visita à Piaçaguera, foi verificado que as escolas oferecem as seguintes refeições: desjejum, almoço, lanche da tarde e jantar. Os cardápios disponibilizados continham desjejum e almoço, sendo que, para as crianças do período da tarde, o lanche da tarde seguia o cardápio do desjejum e o jantar seguia o do almoço. Porém, foi observado que, apesar de o turno escolar ser de meio período, os estudantes realizam as refeições da manhã e da tarde na escola.

Foi observado também que o momento da refeição é diferente das escolas não indígenas, pois, além dos estudantes, outros membros da aldeia também consomem os alimentos preparados na escola. Além disso, as merendeiras têm liberdade para preparar à maneira delas, segundo seus costumes, especialmente preparações com fubá, farinha de mandioca, quirera, mandioca, batata doce, e costumam variar o modo de preparo das carnes e legumes cozidos.
Com relação aos hábitos alimentares, os alimentos ou preparações verificadas nos materiais de consulta sobre Piaçaguera e na visita, como habitualmente consumidos pelos índios, estão descritos no Quadro 1.

Cabe ressaltar que, de todos estes alimentos citados, os cardápios de desjejum apresentaram apenas mandioca e milho, duas vezes no mês. Porém, estes alimentos eram acompanhados por leite com achocolatado ou caramelizado, caracterizando uma prática alimentar contrária à cultura alimentar. E no almoço, o peixe apareceu apenas um dia, dentre todos os cardápios analisados. Por outro lado, foram encontrados alimentos nos cardápios de desjejum e de almoço que não fazem parte do hábito alimentar e que os índios, inclusive, demandavam a retirada do cardápio: bebida láctea, leite caramelizado, mingau industrializado, frango empanado, salsicha, almôndega, linguiça, sobremesas industrializadas como pudim e gelatina, como mostra o Quadro 1.

Quadro 1. Alimentos e preparações que fazem parte dos hábitos alimentares indígenas, e aqueles que não fazem parte, encontrados nos cardápios de desjejum e almoço das escolas da Terra Indígena Piaçaguera, em Peruíbe - SP, em 2016

\begin{tabular}{|c|c|c|c|}
\hline Refeição & $\begin{array}{l}\text { Alimentos e preparações do hábito } \\
\text { alimentar indígena }\end{array}$ & $\begin{array}{l}\text { Alimentos e preparações do hábito } \\
\text { alimentar indígena nos cardápios }\end{array}$ & $\begin{array}{l}\text { Alimentos e preparações que não são } \\
\text { do hábito alimentar indígena nos } \\
\text { cardápios }\end{array}$ \\
\hline Desjejum & $\begin{array}{l}\text { Frutas } \\
\text { Leite com frutas (vitamina), leite puro ou } \\
\text { com café } \\
\text { Pão caseiro } \\
\text { Beiju } \\
\text { Tapioca } \\
\text { Mingau de amido de milho e de fubá } \\
\text { Milho cozido } \\
\text { Mandioca } \\
\text { Bolo caseiro (de milho, por exemplo) } \\
\text { Preparações com farinha de mandioca } \\
\text { (farinha de mandioca com banana, por } \\
\text { exemplo) } \\
\text { Tipá (farinha de trigo, água e sal) } \\
\text { Chá }\end{array}$ & $\begin{array}{l}\text { Mandioca } \\
\text { Milho }\end{array}$ & $\begin{array}{l}\text { Bebida láctea } \\
\text { Leite caramelizado } \\
\text { Mingau industrializado }\end{array}$ \\
\hline Almoço & $\begin{array}{l}\text { Arroz } \\
\text { Feijão } \\
\text { Carne bovina, de frango, de peixe } \\
\text { Sopas } \\
\text { Mandioca, batata doce, inhame, cará } \\
\text { Preparações com banana (farofa e feijão } \\
\text { com banana verde, por exemplo) } \\
\text { Preparações com farinha de mandioca } \\
\text { Preparações com fubá } \\
\text { Quirera } \\
\text { Hortaliças } \\
\text { Frutas } \\
\text { Doces caseiros (curau, arroz doce, } \\
\text { canjica) }\end{array}$ & $\begin{array}{l}\text { Arroz } \\
\text { Feijão } \\
\text { Carne bovina, de frango, de peixe } \\
\text { Batata doce com carne } \\
\text { Quirera com frango } \\
\text { Polenta de fubá } \\
\text { Farofa } \\
\text { Mandioca com carne } \\
\text { Hortaliças } \\
\text { Frutas } \\
\text { Curau e arroz doce }\end{array}$ & $\begin{array}{l}\text { Frango empanado } \\
\text { Salsicha } \\
\text { Almôndega } \\
\text { Linguiça } \\
\text { Pudim industrializado } \\
\text { Gelatina }\end{array}$ \\
\hline
\end{tabular}


Os quadros a seguir mostram as diferenças encontradas entre o cardápio indígena e o não indígena.

Quadro 2. Diferenças encontradas no cardápio de desjejum do Programa de Alimentação Escolar das escolas não indígenas e das indígenas, de agosto de 2016, do município de Peruibe - SP

\begin{tabular}{|c|c|c|}
\hline \multicolumn{3}{|c|}{ Café da manhã } \\
\hline Semana & Cardápio Não Indígena & Cardápio Indígena \\
\hline 1a semana & Leite com achocolatado e biscoito maisena & Leite com achocolatado e mandioca cozida \\
\hline 2a semana & Leite com achocolatado e biscoito maisena & Leite com achocolatado e batata doce cozida \\
\hline 3a semana & Leite com achocolatado e biscoito maria & Leite com achocolatado e milho cozido \\
\hline 4a semana & Leite com achocolatado e biscoito rosquinha de coco & Leite com achocolatado e mandioca cozida \\
\hline 5a semana & Bebida láctea baunilha e biscoito maisena & Leite com achocolatado e batata doce \\
\hline
\end{tabular}

Quadro 3. Diferenças encontradas no cardápio do almoço do Programa de Alimentação Escolar das escolas não indígenas e das indígenas, de agosto de 2016, do município de Peruíbe - SP

\begin{tabular}{|c|c|c|}
\hline \multicolumn{3}{|c|}{ Almoço } \\
\hline Semana & Cardápio Não Indígena & Cardápio Indígena \\
\hline \multirow[b]{2}{*}{ 1a semana } & Arroz, feijão, carne isca com batata, fruta & Arroz, feijão, carne isca com mandioca, fruta \\
\hline & $\begin{array}{l}\text { Arroz, feijão, carne moída, salada de pepino, } \\
\text { pudim de morango }\end{array}$ & $\begin{array}{l}\text { Arroz, feijão, carne moída com abóbora, pudim de } \\
\text { morango }\end{array}$ \\
\hline 3a semana & $\begin{array}{l}\text { Arroz, feijão, carne isca refogada, salada de alface, } \\
\text { fruta }\end{array}$ & Arroz, feijão, carne isca refogada, polenta de fubá, fruta \\
\hline 4a semana & $\begin{array}{l}\text { Arroz, feijão, carne isca refogada, salada de alface, } \\
\text { fruta }\end{array}$ & $\begin{array}{l}\text { Arroz, feijão, carne isca refogada com batata doce, } \\
\text { fruta }\end{array}$ \\
\hline \multirow{2}{*}{ 5a semana } & $\begin{array}{l}\text { Arroz, feijão, carne em cubo, salada de acelga, } \\
\text { gelatina de limão }\end{array}$ & $\begin{array}{l}\text { Arroz, feijão, carne em cubo, com mandioca, gelatina } \\
\text { de limão }\end{array}$ \\
\hline & $\begin{array}{l}\text { Arroz, feijão, carne cubo ao molho, salada de } \\
\text { alface, fruta }\end{array}$ & $\begin{array}{l}\text { Arroz, feijão, carne cubo ao molho com mandioca, } \\
\text { fruta }\end{array}$ \\
\hline
\end{tabular}

Assim, a diferenciação do cardápio indígena consiste, basicamente, em substituir algum alimento do cardápio não indígena por mandioca, batata doce, milho, abóbora e fubá, ou incluí-los em alguma preparação, em um dia da semana.

Como o cardápio não está de acordo com os hábitos alimentares locais, muitas vezes as merendeiras fazem adaptações, variam a forma de preparo dos alimentos $e$ incluem preparações tradicionais na alimentação oferecida nas escolas, como observado durante a visita. Foi verificado, em uma escola, a oferta de uma preparação tradicional indígena que não constava no cardápio: o tipá. Foi observado que a bebida láctea e o leite caramelizado não têm boa aceitação e não faz parte do hábito alimentar consumilos junto com alimentos tradicionais.

Com relação à presença de produtos ultraprocessados, o Quadro 4 apresenta os itens deste grupo identificados em cada refeição, bem como a frequência semanal no cardápio. $O$ pão não foi considerado, pois não havia informação se era industrializado, com inclusão de substâncias e aditivos como ingredientes. 
Quadro 4. Produtos ultraprocessados e frequência semanal no desjejum e almoço do cardápio das escolas da Terra Indígena Piaçaguera, em Peruíbe - SP, em agosto de 2016

\begin{tabular}{|c|c|c|}
\hline Refeição & Produtos ultraprocessados & Frequência semanal \\
\hline Desjejum & $\begin{array}{l}\text { Achocolatado } \\
\text { Biscoito doce } \\
\text { Bebida láctea de vários sabores } \\
\text { Margarina } \\
\text { Flocos de milho açucarado } \\
\text { Iogurte (industrializado) } \\
\text { Biscoito salgado } \\
\text { Rosquinha de leite e de chocolate } \\
\text { Mingau de baunilha e de chocolate (pó para preparo de mingau) } \\
\text { Doce de leite industrializado }\end{array}$ & 7 dias \\
\hline Almoço & $\begin{array}{l}\text { Frango empanado } \\
\text { Almôndega } \\
\text { Linguiça } \\
\text { Salsicha } \\
\text { Mistura para pudim sabores chocolate, morango e baunilha } \\
\text { Gelatina sabores uva, limão e abacaxi }\end{array}$ & 2 a 3 dias \\
\hline
\end{tabular}

Em vez de uma presença mínima de ultraprocessados, como recomenda o Guia Alimentar para a População Brasileira[15], observou-se uma frequência diária desses produtos no desjejum, e em dois dias ou mais da semana, essa refeição é composta exclusivamente por alimentos desse grupo, como por exemplo: bebida láctea e biscoito; iogurte com flocos de milho; mingau de baunilha.

A frequência de itens deste grupo no cardápio do almoço foi de dois a três dias na semana, às vezes contendo dois itens na mesma refeição, como frango empanado e gelatina.

\section{DISCUSSÃO}

Alimentos tradicionais, preparações culinárias que combinam esses alimentos e o modo de comer são parte importante da cultura de um povo, de tal forma que estão intimamente relacionados com a identidade e o sentimento de pertencimento social dos indivíduos ${ }^{[15]}$.

Os resultados deste estudo mostraram que os cardápios da alimentação escolar de Piaçaguera não estavam de acordo com a cultura alimentar da terra indígena, uma vez que eles incluíam apenas alguns alimentos tradicionais e, mesmo assim, estes alimentos não foram incluídos na forma como são habitualmente consumidos pelos indígenas.

Por outro lado, cardápios da alimentação escolar indígena de outros estados do Brasil, como
Santa Catarina e Rio de Janeiro, de 2016, mostraram que é possível incluir alimentos tradicionais e combinar as preparações à maneira do hábito alimentar indígena, como nestes exemplos: espiga de milho cozido e melancia; tipá e suco de fruta; mingau de fubá; mbojape (feijão com carne e farinha de trigo); bolo de milho e maçã $[16,17]$.

Nesse sentido, Giordani et al., verificaram, em 2010, que a alimentação escolar de uma terra indígena no estado do Paraná contemplava as práticas culinárias e os alimentos tradicionais ${ }^{[1]}$.

Cabe ressaltar que uma política pública como o PNAE deve considerar as especificidades culturais e sociais do povo a que se destina e, portanto, a alimentação escolar destinada aos povos indígenas deve ter um caráter diferencial, que respeite o modo de viver dessa população, as crenças, as tradições e a cultura alimentar ${ }^{[1]}$.

O desenvolvimento de uma política diferenciada é um desafio para os gestores públicos ${ }^{[1]} \mathrm{e}$ é necessário que haja a participação social, que a comunidade indígena esteja envolvida por meio de constante discussão e diálogo entre a comunidade e o poder público.

A FAO afirma que há urgência no combate às desigualdades que persistem em grupos populacionais específicos como os indígenas, e que a criação e o fortalecimento de políticas públicas que atendam às 
especificidades desses povos e comunidades tradicionais estão dentre os maiores desafios do Brasil nos próximos anos ${ }^{[18]}$. Dessa forma, são necessários mais estudos com esses grupos populacionais a fim de apoiar a formulação dessas políticas.

Além do aspecto cultural, é necessário se pensar na qualidade da alimentação oferecida nas escolas indígenas, para que seja saudável e adequada, contemplando uma variedade de alimentos frescos in natura e menos produtos industrializados. Nesse sentido, para que os alimentos sejam mais frescos e de melhor qualidade, deve ser priorizada a compra em âmbito local, valorizando os alimentos regionais de pequenos produtores e agricultores familiares ${ }^{[19,20]}$.

O Guia Alimentar para a População Brasileira define que uma alimentação adequada e saudável deve ser, dentre outras coisas, referenciada pela cultura alimentar e recomenda que alimentos in natura ou minimamente processados e preparações culinárias feitas com esses alimentos sejam a base de uma alimentação saudável, enquanto os alimentos ultraprocessados devem ser evitados ${ }^{[15]}$.

Entretanto, os produtos ultraprocessados apareceram com uma alta frequência no cardápio escolar de Piaçaguera, diariamente no desjejum, sendo que esta refeição era muitas vezes composta apenas por estes produtos. Essa frequência poderia ser menor, substituindo os biscoitos por bolo e mingau caseiros, a bebida láctea por chá ou suco de fruta, os embutidos, o frango empanado e a almôndega por carne in natura como o peixe, e as sobremesas doces industrializadas por fruta ou doce caseiro, por exemplo.

\section{Alimentos ultraprocessados são} desbalanceados nutricionalmente, por conter uma alta densidade energética, grandes quantidades de gorduras, açúcar e sódio e, por outro lado, baixa quantidade de fibras e micronutrientes. Padrões alimentares caracterizados pela presença frequente desses alimentos podem levar ao aparecimento precoce de doenças relacionadas a uma alimentação inadequadal ${ }^{[21]}$.

Alguns estudos têm mostrado que alimentos industrializados, incluindo os ultraprocessados, estão cada vez mais presentes no hábito alimentar de comunidades indígenas $[5,6,7,8]$. O estudo de Ribas et al. (2001), realizado em uma comunidade indígena do Mato Grosso do Sul, mostrou que a dieta das crianças contemplava alimentos industrializados como extrato de tomate, refresco em pó, refrigerante, linguiça, bala, pães e biscoitos. Além disso, o estudo encontrou que a alimentação das crianças não atendia às recomendações nutricionais vigentes de acordo com a faixa etária[].

Os resultados de Piaçaguera corroboram com outros estudos sobre a alimentação escolar indígena no Brasil. Castro et al. (2014), ao avaliarem os cardápios do PNAE de todas as 35 escolas Kaingáng do Rio Grande do Sul, em 2008, encontraram uma inadequação dos cardápios, caracterizada pela baixa oferta de hortaliças, leguminosas, frutas e de leite e derivados ${ }^{[22]}$.

Pessôa (2013) avaliou, em 2011 e 2012, o cumprimento das diretrizes do PNAE em escolas da Terra Indígena Buriti, Mato Grosso do Sul, e verificou grande frequência de alimentos industrializados nos cardápios ${ }^{[23]}$.

Dessa forma, é observado um descumprimento da diretriz do PNAE, referente ao emprego da alimentação saudável e adequada, compreendendo o uso de alimentos que respeitem a cultura, as tradições e os hábitos alimentares saudáveis ${ }^{[1]}$, em comunidades indígenas no Brasil.

\section{CONCLUSÕES}

O presente estudo concluiu que o cardápio da alimentação escolar da Terra Indígena Piaçaguera, no estado de São Paulo, não estava de acordo com os hábitos alimentares dessa população, que o cardápio escolar indígena é pouco diferenciado do não indígena e que os produtos ultraprocessados estavam presentes com elevada frequência.

Estes resultados retratam uma situação de ameaça à soberania alimentar desse povo e mostram que o Programa de Alimentação Escolar não tem sido uma política de promoção da Segurança Alimentar e Nutricional para esses estudantes indígenas.

Finalmente, é necessário que o planejamento do cardápio considere a variedade de alimentos tradicionais e valorize os saberes e o patrimônio alimentar dessa comunidade. 


\section{REFERÊNCIAS}

[1] Giordani RCF, Gil LP, Auzani SCS. Políticas públicas em contextos escolares indígenas: repensando a alimentação escolar. Espaço Ameríndio. 2010;4(2):25-51.

[2] Food and Agriculture Organization of the United Nations. O estado da segurança alimentar e nutricional no Brasil: um retrato multidimensional. Brasília (DF): FAO; 2014.

[3] Comissão Pró-índio de São Paulo. Uma notícia dessa é um alívio tão grande! Terra Indígena Piaçaguera Homologada! [Internet]. São Paulo; 2016 [acesso em 17 jan 2017]. Disponível em: http://comissaoproindio.blogspot.com.br

[4] Segall-Corrêa AM, Oliveira BC, Ferreira MBR, Azevedo MMA, León-Marin L, Kepple AW, et al. Estudo dos conceitos, conhecimentos e percepções sobre segurança, insegurança alimentar e fome em quatro grupos de etnia Guarani no estado de SP: relatório técnico. Campinas: UNICAMP; 2009.

[5] Moura PG, Batista LRV, Moreira EAM. População indígena: uma reflexão sobre a influência da civilização urbana no estado nutricional e na saúde bucal. Rev. Nutr. 2010;23(3):459-465.

[6] Ribas DLB, Sganzerla A, Zorzatto JR, Philippi ST. Nutrição e saúde infantil em uma comunidade indígena Teréna, Mato Grosso do Sul, Brasil. Cad. Saúde Pública. 2001;17(2):323-331.

[7] Souza KLPCR. O Programa Nacional de Alimentação Escolar em comunidades indígenas de Porto Seguro - BA: um estudo na perspectiva da segurança alimentar e nutricional [dissertação]. Salvador: Universidade Federal da Bahia; 2013.

[8] Katz E. Alimentação indígena na América Latina: comida invisível, comida de pobres ou patrimônio culinário? Espaço Ameríndio. 2009;3(1):25-41.

[9] Comissão Pró-índio de São Paulo. Alimentação nas escolas indígenas: desafios para incorporar práticas e saberes. São Paulo: Comissão Pró-índio; 2016.

[10] Burity V, Franceschini T, Valente F, Recine E, Leão M, Carvalho MF. Direito Humano à Alimentação Adequada no contexto da Segurança Alimentar e Nutricional. Brasília (DF): ABRANDH; 2010.

[11] Brasil. Resolução CD/FNDE no 26, de 17 de junho de 2013. Dispõe sobre o atendimento da alimentação escolar aos alunos da educação básica no âmbito do Programa Nacional de Alimentação Escolar - PNAE. Diário Oficial da União. 18 jun 2013.

[12] Comissão Pró-índio de São Paulo [internet]. São Paulo; 2008 [acesso em 15 out 2016]. Disponível em: http://www.cpisp.org.br

[13] Fundo Nacional de Desenvolvimento da Educação. Clientela atendida pelo PNAE (Censo Escolar) [internet]. Brasília: FNDE;
2016 [acesso em 15 jun 2016]. Disponível em: http://www.fnde.gov.br

[14] Prefeitura Municipal da Estância Balneária de Peruíbe. Peruíbe: Boletim Oficial do Município, número 691, ano XIX [internet]. Peruíbe; 2016 [acesso 10 agosto 2016]. Disponível em: http://www.peruibe3.sp.gov.br

[15] Brasil. Ministério da Saúde. Guia Alimentar para a População Brasileira. 2.ed. Brasilia (DF): MDS; 2014.

[16] Secretaria de Estado da Educação. Cardápios indígenas - 2016 [Internet]. Santa Catarina; 2016 [acesso 25 set 2016]. Disponível em: http://www.sed.sc.gov.br

[17] Secretaria de Estado da Educação. Cardápio Indígena [Internet]. Rio de Janeiro; 2016 [acesso 25 set 2016]. Disponível em: http://www.ri.gov.br

[18] Food and Agriculture Organization of the United Nations FAO. O estado da segurança alimentar e nutricional no Brasil: um retrato multidimensional. Brasilia (DF): FAO; 2015.

[19] Gonçalves HVB, Cunha DT, Stedefeldt E, Rosso VV. Family farming products on menus in school feeding: a partnership for promoting healthy eating. Cienc. Rural. 2015;45(12):2267-2273.

[20] Teo CRPA, Monteiro CA. Marco legal do Programa Nacional de Alimentação Escolar: uma releitura para alinhar propósitos e práticas na aquisição de alimentos. Rev. Nutr. 2012;25(5):657-668.

[21] Rauber F, Campagnolo PDB, Hoffman DJ, Vitolo MR. Consumption of ultra-processed food products and its effects on children's lipid profiles: A longitudinal study. Nut. Metab. \& Cardio. Diseases. 2015;25(1):116-122.

[22] Castro TG, Matos ELC, Leite MS, Conde WL, Schuch I, Veiga J et al. Características de gestão, funcionamento e cardápios do Programa Nacional de Alimentação Escolar em escolas Kaingáng do Rio Grande do Sul, Brasil. Cad. Saúde Pública. 2014;30(11):24012412.

[23] Pessôa MCMB. Programa Nacional de Alimentação Escolar em escolas da Terra Indígena Buriti - Mato Grosso do Sul [dissertação]. Campo Grande: Universidade Federal de Mato Grosso do Sul; 2013. 